\title{
Author Index / Subject Index Vol. 16, No 3-4, 1994
}

Aschner, M. 222 Banati,R.B. 114 Battistini, L. 152 Bredesen, D.E. 207 Brosnan,C.F. 152 Campbell, I.L. 212 Casadevall, A. 152 Chao, C.C 172 Charles, A.C. 196 Chiang, C.-S. 212 Dave,V. 222 Dickson, D.W. 152 
George, J. 128 Giulian,D. 128 Goderie,S. 222 Graeber,M.B. 114 Hu,S. 172 Janabi,N. 137 KesslerJ.A. 180 Kimelberg,HX 222 Lee,S.C. 152 Li, J. 128 Li,X. 128 Lipton,S.A. 145 
Mackenzie-Graham, A J. Mehler,M.F. 180 Merrill, J.E. 113,162 Mitrovic,B. 162 MuUaney,KJ. 222

Rabizadeh, S. 207 Raine,C.S. 152 Rutecki,P.A. 128 Samimi,A. 212 Smoll,A. 162 Stalder.A. 212

Tardieu,M. 137 


\title{
Subject Index Vol. 16r No. 3-4,1994
}

\author{
AIDS 128,145 \\ Alzheimer's disease 128 \\ Apoptosis 162,207 \\ Arachidonate 145 \\ Aspartate uptake 222 \\ Astrocyte(s) 114,137,145,152 162,196, \\ 222 Astrocytosis 212
}

Bone morphogenetic proteins 180 Brain injury 128 - macrophages 114 Colony-stimulating factors

180 Communication 196 Cryptococcusneoformans 152 Cysteine 145

Cytokine(s) 128,145,152,180,212 Cytotoxicity 114 Degeneration 207 Dementia 145 Differentiation

180 Excitotoxicity 172 Free radicals 145 Gap junction 196 Glia 128 
Glial cell 196

Glutamate 145

- uptake 172

Glutamine synthetase 172 .

gpl20 145

Hematolymphopoiesis 180

HIV-1 137

HTV-1-associated cognitive/motor complex

145 Host response 212 Human neurodevelopment 137 Inflammation 152 Interferon^^ 145

Interleukin-lp 145 Interleukin-6 145 Interleukins 180 Intracellular calcium 196 Macrophages $145 \mathrm{~N}$ -

Methyl-.D-aspartate receptor 145 Methylmercury 222 Microglia 128,137,145,152,162 Microglial

activation 114 Microgliosis 212 Multiple sclerosis 152 
Necrosis 162

Nerve growth factor receptor 207

Neuron(s) 128,145

Neuronal development 172

Neuropathology 137,212

Neuroprotection 114

Neurotoxicity 145,222

Neurotrophics) 180,207

Nitric oxide 145,152,162

Oligodendrocyte(s) 162,196

Phagocytosis 114

Platelet-activating factor 145

Quinolinate 145

Rat 222

Serotonin 222

- uptake 222

Signal transduction 180

Stroke 128

Tat 145

Transgenic mice 212

Tumor necrosis factor-a 145,172

Tyrosine kinase 180 